The pain still persisted. Apart from an "interval " appendicectomy two years previously she had been quite healthy. Menstruation began at 14 and had been quite regular, with normal loss.

On admission her general condition was good ; the mucous membranes were of normal colour; pulse 92 , temperature $97.8^{\circ} \mathrm{F}$. $\left(36.55^{\circ} \mathrm{C}\right.$.), respirations 20 , blood pressure $118 / 70$. The abdomen was not distended, the wall moved freely, the umbilicus was not discoloured. There was slight tenderness in the left iliac fossa, but rigidity or free fluid was not detected. Examination per vaginam showed healthy vulva and urethra, softish mobile cervix. There was no enlargement of the uterus, which was anteverted, but any attempt to move it caused great pelvic pain. A tender illdefined solid mass about 2 in. $(5 . \mathrm{cm}$.) in diameter was palpable in the pouch of Douglas, apparently continuous with the left adnexa. The right appendages were normal. Per speculum a healthy nulliparous cervix was seen.

The urine was normal. A blood count showed: leucocytes, 8,100 ; erythrocytes, 4,000,000; haemoglobin, $90 \%$. A tentative diagnosis of a left ectopic pregnancy was made.

On the sixth day after admission a profuse vaginal haemorrhage occurred with moderate pain in the left iliac fossa. Exploratory laparotomy was then decided upon.

Operation.-This was carried out by one of us (L. G.) on October 26. On opening the abdomen the peritoneum was normal in colour, and no free blood was seen. Uterus, tubes, and right ovary were normal in appearance. The omentum was adherent to the posterior aspect of the uterus and left broad ligament by filmy adhesions which separated readily, revealing the left ovary, to which was attached a mass of blood clot the size of a tennis ball. Adjacent loops of adherent bowel were peeled off easily and the mass and about half of the ovary were removed. No corpus luteum was seen on the right ovary, nor was there macroscopic evidence of endometriosis. The abdomen was then closed in layers.

Convalescence was uneventful ; the patient was ambulant on the fourth day and was discharged on the ninth postoperative day. Salpingography performed on November 26 showed patency of both tubes.

Pathological Report (J.E.).- “ The specimen consists of about half of an ovary, to the free surface of which is attached a firm laminated egg-shaped mass of blood clot $4 \mathrm{~cm}$. in diameter. On the cut surface of the ovary a corpus luteum of pregnancy $1.5 \mathrm{~cm}$. in diameter is visible. On breaking away fragments of blood clot, villi are seen in the neighbourhood of the corpus luteum and adjacent ovarian tissue. No foetus was found. Sections show syncytial masses and chorionic villi embedded in the ovarian tissue and invading the corpus luteum. Many of the villi are already degenerated. The ovarian stroma is exceedingly vascular, but no pseudo-decidual cells are evident; the zonal layer is heavily infiltrated with polymorphs, plasma cells, and macrophages, but this reaction is not seen elsewhere in the ovary. The histological picture of the corpus luteum coincides with that of an early pregnancy, with the central core occupied by a recent organizing clot. There is no evidence of ovarian endometriosis."

We wish to thank Professor E. Farquhar Murray for his helpful suggestions and for permission to publish this case, and Mr. D. Harland for his technical assistance.

$$
\begin{aligned}
& \text { L. GANZ, F.R.C.S.Ed., M.R.C.P.I., } \\
& \text { Senior Registrar, Department of Gynaecology. } \\
& \text { J. E. ENNIS, M.B., B.S., } \\
& \text { Consultant Pathologist. }
\end{aligned}
$$

\section{Drybusn Hospital,} Durham.

\section{REFERENCES}

Bolton, John P. (1949). Ohio St. med. J., 45, 353. Curtis, A. H. (1941) Surg. G ynec. Obstet. 72, 1039. Deweese, W. J. (1949). Minn. Med., 32, 272.

Isbell, N. Paul, and Båcon, W. B. (1947). Amer. J. Obstet. Gynec., 54, 329.

Novak, Emil (1947). Gynaecological and Obstetrical Pathology, 2nd ed., p. 455. Saunders, Philadelphia.

Way, S. (1941). Brit. J. Obstet. Gynaec., 48, 473.

\section{Strangulated Spigelian Hernia}

Spigelian hernia occurs along the semilunar line, usually near the level of the arcuate ligament. It penetrates the broad fascial band by which the internal oblique and transversalis muscles are inserted into the rectus sheath, but lies under the aponeurosis of the external oblique muscle. This tense aponeurosis obscures the tumour and makes it difficult to palpate. The hernia has a tough rigid neck and is often covered by a thick layer of extraperitoneal fat.

\section{CASE Report}

A stout woman aged 65 , with a lax pendulous abdomen, had a history over several years of periodic abdominal distension and vomiting, sometimes with icterus of the skin and typical gall-bladder colic. Cholecystectomy was performed in August, 1947. The gall-bladder was small and packed with stones; the common duct was free of stones. Colic and icterus were immediately relieved, but the attacks of distension and vomiting continued unabated, and became more frequent as time passed.

On May 20,1949, she developed sudden severe pain in the right iliac fossa. This pain travelled slowly to the epigastrium, and then became generalized. The most severe pain was constantly in the right iliac fossa. Vomiting began 12 hours after the onset of symptoms and became very frequent and voluminous. She was admitted to Mr. J. Campbell's surgical unit in the Southport Promenade Hospital 20 hours after the onset of symptoms. On admission her temperature, pulse, and respiration were normal. Dehydration was obvious and proclaimed the violence of the vomiting. Tenderness in the right iliac fossa was extreme. The patient winced when the examining hand had done little more than touch the skin. A tense oval swelling about 3 by 2 in. $(7.5$ by $5 \mathrm{~cm}$.) was palpated in the right iliac fossa, lying within the substance of the abdominal wall, parallel with the inguinal ligament and about $2 \frac{1}{2}$ in. $(6.25 \mathrm{~cm}$.) above it.

Strangulated Spigelian hernia was diagnosed. An incision was made over the swelling and the hernia was revealed after the external oblique aponeurosis had been incised. The sac contained omentum and strangulated loops of small intestine, which were kinked and bound together by tough adhesions, suggesting a fairly prolonged tenancy in rather inadequate quarters. The neck was rigid and grasped the sac tightly; it was big enough to admit two fingers. The worst of the adhesions were divided, and the intestine was returned to the abdomen, where normal colour was rapidly regained. The layers of the abdominal wall were defined and the wound repaired. Recovery was uneventful.

\section{COMMENT}

This case is interesting, as the apparent continuation of symptoms following cholecystectomy were ascribed to some residual liver damage for which she had been treated. The onset of acute strangulation at first closely imitated acute appendicitis. The correct diagnosis was given by the development of intestinal obstruction with the presence and site of the tumour.

Reid (1949) reports a case of Spigelian hernia which imitated an acute appendicitis to perfection. The above case illustrates how deceptive this rare hernia can be and the advisability of bearing it in mind when abdominal symptoms of an obscure nature are found.

We thank Mr. John Campbell for permission to publish details of this case.

$$
\begin{aligned}
& \text { D. Watson, M.B., Ch.B. } \\
& \text { Betty Scotter, M.B., B.8. }
\end{aligned}
$$

